\title{
E-LOOX, A HYBRID LEARNING MANAGEMENT SYSTEM
}

\author{
Bilal Gonen and Badri Jimale \\ School of Information Technology, University of Cincinnati, Cincinnati, Ohio, U.S.A.
}

\begin{abstract}
E-loox is an educational software application that has been designed specifically for students located in areas with limited Internet access. Unlike the majority of existing educational applications, E-loox is a "hybrid app"- meaning it can function both on and offline. As a hybrid app, E-loox allows students to complete assignments, access course materials, and conduct research in places where there is no Internet access. While global Internet access has expanded rapidly in the last decade, there are still more than 3.5 billion people who lack access, including approximately 60 million people in the United States. E-loox seeks to bridge the gap for the millions of students who have internet in the classroom but lack a home connection.
\end{abstract}

\section{KEYWORDS}

Education; Cloud-based LMS; E-loox; Learning management system

\section{INTRODUCTION}

In the last three decades the use of technology in modern day classrooms has become ubiquitous [1]. The days of chalkboards has long past and the flood of technological innovations has overtaken the traditional methods of learning. Evidence of the world-wide spread of e-learning is easy to obtain. According to Paulsen [2], much of the success of e-learning can be attributed to the availability of Learning Management Systems (LMS), also known as learning platforms or Virtual Learning Environments (VLE). An LMS is a system that enables an institution to develop electronic learning material for students, offer courses electronically, evaluate and test students electronically and to electronically generate student's databases in which the progress and results of students can be charted.

The conversion from traditional classrooms to online learning platforms follows the transformation of learning theories from the behaviorist orientation that portrays learning as a passive activity to a theorist orientation that emphasizes the active, social and reflective nature of learning. Learners are today regarded the active acquirers of knowledge as opposed to passive recipients. As this trend becomes the norm in learning institutions all over the world, questions have emerged regarding the Learning Management System (LMS) most suitable for an online course. With an increasing number of LMSs, it is becoming difficult to determine which one to go for.

According to Cavus and Zabadi [3], the success of students depends heavily on the selected LMS. At the center of every LMS selection should be the students' needs coupled with the objectives of the online course. An LMS that allows an instructor to engage students in an active learning environment should be rated at the top of all available LMS alternatives. It is critical for a potential user to understand the strength and weaknesses of an LMS before making a selection. 
International Journal of Software Engineering \& Applications (IJSEA), Vol.12, No.1, January 2021

Selecting the right LMS is important because some open source Learning Management Systems have unnoticeable costs and unclear terms attached and some proprietary and cloud-based LMSs are not as efficient as they claim to be [3]. This makes it important to understand each Learning Measurement Systems as an individual system. In order to develop a great understanding of an LMS, users can compare and contrast between existing systems. The selection of the right LMS even becomes more vital when the choosing country is one with limited resources.

Education is one of the highest priorities among developing nations, as there is a direct connection between quality education and economic and social development. The United Nations' 2030 Sustainable Development Goals prioritize education as its fourth goal, which reads "ensure inclusive and equitable quality education and promote lifelong learning opportunities for all." [4]. For both developed and developing nations, access to the Internet is a catalyst for education at all levels. The 2016 World Bank's report entitled Education Quality and Economic Growth states that the Internet can improve education by opening doorways to a wealth of information, knowledge, and educational resources, increasing opportunities for learning inside and outside of the classroom. Interactive teaching methods and distance learning opportunities can help rectify inequalities in education experienced by girls and women. Additionally, access to the Internet helps educational administrators to reduce the costs and improve the quality of schools and colleges [5].

Despite global efforts to make quality education available to all students, a lack of broadband connectivity is preventing widespread use of the Internet in education and other areas of life in many countries. Without access to the Internet, students in developing countries (and students in rural and impoverished areas of developed countries) lack critical resources to advance their education. Students without Internet access are on the wrong side of the digital divide - missing out on opportunities to do independent research, interact with educators and other students, and enroll in distance learning courses. Rather than narrowing the gap to quality education for those in developing countries, widespread access to the Internet is actually perpetuating inequities among developed and developing countries [6]. This paper outlines the scope of the issue, an innovative solution to accelerate students' learning in areas with limited Internet access, and the potential social impact.

\section{OBJECTIVES AND NEEDS}

While Internet access has expanded rapidly since the 1990s, bringing significant educational benefits to students around the world, there are still a staggering number of people without access. The International Telecommunication Union's Information and Communications Technologies (ICT) Facts and Figures 2017 provides the following insights regarding Internet access across the globe:

1. $70 \%$ of the world's youth are online, while approximately $30 \%$ lack access.

2. In developed countries, 94\% of young people aged 15-24 use the Internet compared with $67 \%$ in developing countries and only $30 \%$ in Least Developed Countries (LDCs).

3. Only $15 \%$ of households in LDCs have Internet access at home. In these countries, many Internet users are accessing the Internet from work, schools and universities or from other shared public connections outside the home.

4. Mobile-broadband subscriptions have grown more than $20 \%$ annually in the last five years and are expected to reach 4.3 billion globally by end 2017. Despite the high growth rates in developing countries and in LDCs, there are twice as many mobile-broadband subscriptions per 100 inhabitants in developed countries as in developing countries, and four times as many in developed countries as in LDCs 
Even in countries with wide spread access, the continuity of the network can be problematic. Lack of Internet access, unreliable networks, limited band width and high latency will continue to pose major barriers to students in developing countries [7].

\section{Proposed Solutions}

The research in the previous section demonstrates that as the Internet becomes increasingly accessible in developing nations, there are emerging opportunities to use it as a tool to advance education. However, while a growing number of students are able to access to the Internet in schools, libraries, or other public educational institutions, fewer are able to do so at home. E-loox is an educational software application that has been designed specifically for students who lack reliable home Internet access. As a hybrid app (one that can function both on and offline), E-loox is an innovative tool that advances distance learning opportunities. With E-loox, students can complete assignments, access course materials, and conduct research in situations where there is no internet access. How it works: Similar to a USB or E-reader, students can download course contents and files to use offline when they have an Internet connection. Unlike a USB oran Ereader, E-loox provides students with a full, interactive platform that can be accessed offline. For example, with E-loox's offline features, students can complete interactive equizzes and assignments offline. When students regain internet access in the classroom, E-loox automatically syncs the work Students have completed offline so they can review, collaborate, and continue the lesson in the classroom.

\subsection{Functionality \& Features}

The application will be available for both Android and iOS. Once installed, E-loox can function completely offline, as the app will be hosted in the cloud. Up on logging into E-loox, users enter their homepage where they can view all of the courses they are currently enrolled in. Screen shots of both the E-loox Log in page and homepage are shown below:

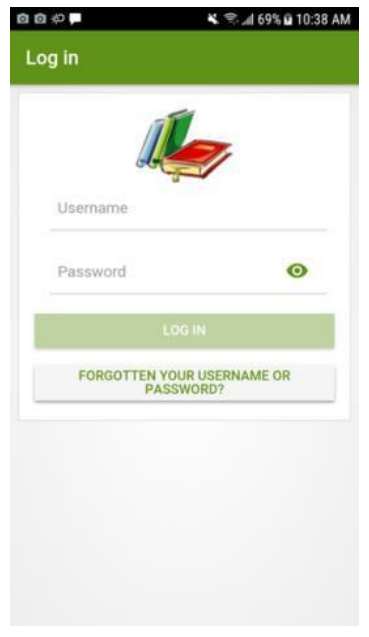

Figure 1. E-loox login page

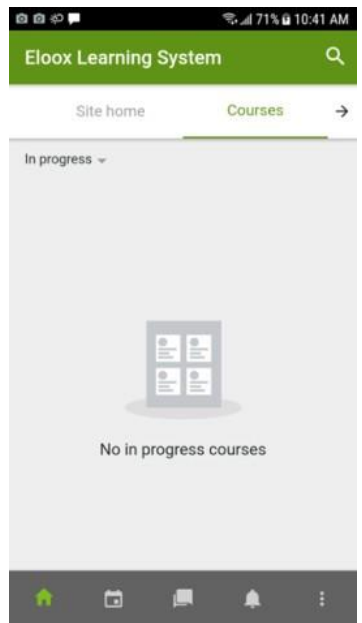

Figure 2. E-loox home page

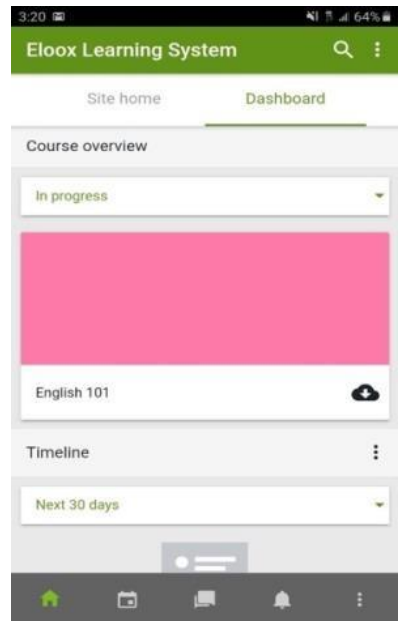

Figure 3. Downloadable Content

When a student is actively enrolled in a course, the following features are available:

Assignments: Users can access previous, current, and future assignments. Instructors can post homework, quizzes, and exams to the assignments page. 
International Journal of Software Engineering \& Applications (IJSEA), Vol.12, No.1, January 2021

Calendar events: Users can view the interactive calendar, where the instructor can post the dates of quizzes, exams, and major assignments. Students can also add events to the calendar.

Message boards: Both instructors and students can use the interactive message boards to communicate with each other. When offline, students can still view message board forums that have been synced to their device.

Notifications: The application has a built-in notification feature.

Grades: Users can view all of their grades for the course using the grades feature

Downloads: The downloads feature enables students to access materials that have been downloaded to the device for offline use. As Figure 3 shows, there is a cloud sign with downward arrow indicating that the course is downloadable. This feature enables students to download content in their own Android powered devise.

\subsection{Built-in Alert System}

It is known that storage is crucial for the performance of handheld devises. With this in mind, Eloox was designed to warn users before content is downloaded. Figure 4 shows the message informing users of how much space is needed to download for the content. Figure 5 shows that the user will be able to see the course/courses enrolled once they login.

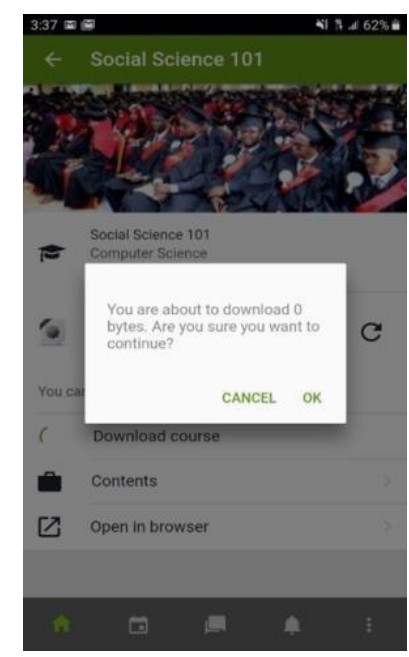

Figure 4. Warning one receives before content is downloaded

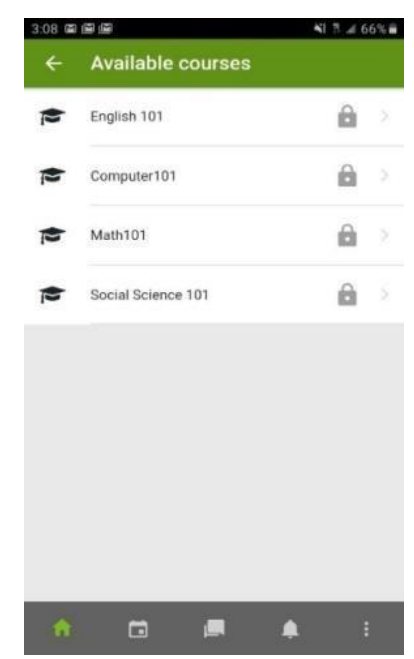

Figure 5. List of available courses to this user

Additionally, E-loox has a built-in library, and databases that would allow students to conduct research. This feature is vital, as many developing countries lack educational resources such as public libraries. With both offline and online capabilities, E-loox can help close the digital divide for students who lack internet access at home.

\section{Ongoing EFFort to LaUnCh E-LoOX in Somalia}

The developer of E-loox has established relationships with educators and governmental agencies in Hargeisa, Somalia. As the developer prepares to launch E-loox, they have begun to leverage these relationships to cement a strong user-base upon launching. Somalia's schools struggle 
International Journal of Software Engineering \& Applications (IJSEA), Vol.12, No.1, January 2021

disproportionately in the digital era and would reap significant benefits from incorporating Eloox into everyday curriculum. The Somalia Education Cluster's 2016 Annual Report (released in

January of 2017), highlighted the following research that provides insight into the potential market for E-loox:

1. Somalia has one of the world's lowest gross enrolment rates for primary school aged children with only 30 percent children at primary education level and 26 percent for secondary education. Newly published data from United Nations Population Fund (UNFPA) suggest that the number of out- of-school children and youth aged 6-8 years is at 3 million which is a significant increase compared to the previously estimated 1.7 million out-of-school children. The majority of out-of-school children are found in Central and South Somalia.

2. In total 142 learning centers shut down and 61 others were on the brink of closure with limited possibilities of maintaining operation in the 2016-17 academic year. The majority of the affected schools were in Banadir, Lower Shabelle, Middle Shabelle, Bay and Galgaduud regions.

In Hargeisa, where E-loox's developer has been building relationship, the educational situation is no better than Somalia as a whole. According to Hali Access Network's 2015 report on education in Somaliland, "By nearly every indicator, Somaliland's education system is broken. Less than one-third of all primary school-aged Somaliland children are enrolled in primary school at all. Of those that start, fewer than $60 \%$ make it to fifth grade on time. At the secondary level, fewer than $10 \%$ of secondary school-age children are enrolled. Despite a nominally English curriculum, classes are taught in Somali or Arabic, and students graduate from secondary schools unable to form simple sentences in English and knowing some math but only through rote memorization" [8].

\subsection{Outcomes and Impact}

According to a recent OECD report, providing every child with access to education and the skills needed to participate fully in society would boost GDP by an average $28 \%$ per year in lowerincome countries and $16 \%$ per year in high-income countries for the next 80 years. The body of research that connects quality education to positive societal development is vast and indisputable. According to the book, Educational Quality and Economic Growth "Education in every sense is one of the fundamental factors of development. No country can achieve sustainable economic development without substantial investment in human capital. Education enriches people's understanding of themselves and world. It improves the quality of their lives and leads to broad social benefits to individuals and society. Education raises people's productivity and creativity and promotes entrepreneurship and technological advances. In addition, it plays a very crucial role in securing economic and social progress and improving income distribution" [5].

A careful comparison of the three systems; E-loox, Google Classroom, and Moodle is achieved in this paper. The comparison takes into consideration a variety of features ranging from content development, bulletin board/discussion area, group participation, calendar, student study tools, monitoring students' progress and participation, navigation, offline features and interface amongst many other aspects. 
International Journal of Software Engineering \& Applications (IJSEA), Vol.12, No.1, January 2021

\section{Moodle ANd Google Classroom}

\subsection{Moodle}

According to Costa et al. [9], Moodle (Modular Object-Oriented Dynamic Learning Environment) represents one of the most popularly used open-source e-learning platforms that enables the creation of a course website and ensuring it is accessible to students. Introduced in 2002 , the tool has been developed to support the constructive and social approach to education.

This online platform enables the exchange of information through synchronous and asynchronous communication amongst users geographically dispersed. It can support the part-time, full-time and distance form of study. It is available free of charge as an open software under the GNU General Public License and can be run on a tablet, computer or a smartphone equipped with a web viewer connected to the internet [9].

Functionally, this system has easily configurable features making it possible to create student assessment processes (online tests, quizzes and surveys), as well as using a timetable to manage the tasks. The system also provides a variety of complementary tools to support both teachers and learners [10]. As an online tool, Manenova [11] highlights the strengths of Moodle in the "Course administration" features, where access to selected files can be limited by the administrator or password-protected, Organization and Configuration, since it is based on a template principles that has easy navigation and intuitive interface, Sources and content are available in various formats (html, tests, audio and video, graphics format), testing and evaluation take a traditional approach, cooperative learning which runs in pairs and groups and allows for a socialconstructive learning approach using synchronous and asynchronous communication methods.

\subsection{Google Classroom}

Zhang [12] defines the Google classroom as "a Learning Management System (LMS) offered by Google to teachers. It provides a central location from where teachers can communicate with students, create assignments and pose questions (p.6)." In a world that is increasingly becoming revolutionized by technology, Google Classroom enables today's digital learner to use an internet empowered platform to learn. Like all new applications, Google Classroom has its own set of unique traits; it begins as a blank canvas where teachers set up online classes for their physical classrooms. Teachers are able to add students to a class, upload course materials, and create assignments and announcements [12].

Google classroom combines a variety of Google features to help educators adopt a paperless system[13]. It ties together the Gmail feature of Google for communication, Google Drive for assignment creation and sharing, Google calendar for scheduling classes and Google Sheets, Slides and Docs for writing. For effectiveness, students have to set up the Google Classroom app on their computers, mobile devices and chrome books. Additionally, they have the apps associated with the Google Classroom. This is because failure to do so may lead to the student missing out on valuable information or material in the classroom. For instance, failure to install the Google Doc app may make it impossible for students to access a Google Doc document attached in the class.

\section{OPEN-Source Vs. Premium LMS}

Cavus and Zabadi [3] describe an Open Source LMS as the source code of a software that is readily made available to the public for modification and extension depending on the needs of the 
users. The open source community accepts 10 items namely; source code, free distribution, integrity of authors code, derived works that allow for modification, distribution of license, license that is technologically neutral, license that is not specific to a product, license that is not restrictive of other software, no corresponding author, no discrimination of groups or individual users or academic fields.

Unlike Commercial LMS that are availed to the market at a price, Open-source LMS are available at no cost. These LMSs are available in an efficient way that promotes learning and economic value to users who can readily access it. Open Source LMSs help institutions to upgrade their educational standards to meet the threshold of modern-day education that has been technologically revolutionized; not every Open Source LMS have all features needed to conduct successful learning objectives. For example, often times Open Source products do not have dedicated technical support, and this is one of the elements that separates E-loox from Moodle and Google Classroom. Phone technical support will be offered when E-loox is fully launched. This will make the process of adopting E-loox easier.

Google Classroom and Moodle are all open-source LMSs. They are accessible under a public free license hence users have the right to use, change, create, and distribute to anyone and for any purpose. In other words, these systems have, in other words, been donated by developers to the members of the public and for public interest [14]. They were developed as a better alternative to the propriety LMSs from a financial perspective, involving less costs related to software maintenance and license, requiring a less-developed infrastructure and most importantly, allowing users to develop their own LMS based on their specific goals, requirements and necessities.

\subsection{Content Development}

Content Development is a significant area in the designing of a course. The effectiveness of an LMS remains a fundamental aspect of content development [15]. An online course should be student-centered to motivate and support learners. The course content and how it is uploaded reflects on the effectiveness of the course. It is also important for an online course to have an option that allow instructors to make changes and create content relevant to the learner's needs and abilities.

All the three aforementioned Learning Management Systems allow users to upload files from their PCs to the server. This is particularly useful when turning in assignments and sharing documents. While it is possible to upload multiple files zipped in one folder at once on E-loox, this is impossible in both Google Classroom and Moodle where files have to be uploaded one after the other, even those that fall under the same title. Additionally, in both E-loox and Google classrooms, instructors can release content based on a chronological criterion. In Google classrooms for example, newer materials will appear closer to the top of the page. According to Zhang [12], this makes possible for instructors to plan which files they want to make readily accessible to students on the classroom page. This chronological appearance of files is not possible in the Moodle Learning Management system. While E-loox enables students and instructors to edit uploaded texts online, this feature is not available in both Moodle and Google Classroom systems. A user has to edit a text material offline before uploading it. Table 1 displays these similarities and differences. 
International Journal of Software Engineering \& Applications (IJSEA), Vol.12, No.1, January 2021

Table 1: Content Development

\begin{tabular}{|l|l|l|l|}
\hline \multicolumn{1}{|c|}{ Instructors can } & \multicolumn{1}{c|}{ E-loox } & Moodle & Google Classroom \\
\hline Upload files from desktop to server & $\checkmark$ & $\checkmark$ & $\checkmark$ \\
\hline $\begin{array}{l}\text { Upload multiple files at once. The files } \\
\text { have to zipped into one file once. }\end{array}$ & $\checkmark$ & & \\
\hline Edit uploaded texts online & $\checkmark$ & & \\
\hline $\begin{array}{l}\text { Release content based on } \\
\text { chronological criteria }\end{array}$ & $\checkmark$ & & $\checkmark$ \\
\hline Fully featured offline & $\checkmark$ & & \\
\hline
\end{tabular}

\subsection{Group Participation}

E-loox shares some similarities with Moodle and Google Classroom. All three platforms enable students to work together in small groups. They can chat, share documents, send emails and work together in synchronous and asynchronous environments. This is a significant advantage to students who live far away from each other and are unable to meet physically. All three systems allow instructors to create groups manually, sharing of files amongst group members, and email communication amongst users. These activities all aim towards achieving a maximum interaction amongst learners. In all three Learning Management Systems, group members can have a private chat area. This means that a chat area remains exclusive for the members of a particular group and no one outside the group can view posts or post on that area. Additionally, while E-loox allows group members to have private bulletin boards, the same does not apply to Moodle or Google Classroom where all members of the classroom have access to the Bulletin Board. The following table summarizes group participation in the three LMSs.

Table 2: Group Participation

\begin{tabular}{|l|l|l|l|}
\hline \multicolumn{1}{|c|}{ Feature } & \multicolumn{1}{|c|}{ E-loox } & \multicolumn{1}{c|}{ Moodle } & \multicolumn{1}{c|}{ Google Classroom } \\
\hline Instructors can create groups manually & $\checkmark$ & $\checkmark$ & $\checkmark$ \\
\hline Users can email group members & $\checkmark$ & $\checkmark$ & $\checkmark$ \\
\hline Group members can share files. & $\checkmark$ & $\checkmark$ & $\checkmark$ \\
\hline Group members can have a private chat area & $\checkmark$ & $\checkmark$ & $\checkmark$ \\
\hline $\begin{array}{l}\text { Group members can have private bulletin } \\
\text { boards. }\end{array}$ & $\checkmark$ & & \\
\hline
\end{tabular}

\subsection{Discussion Area/Bulletin Boards}

An effective online class goes beyond sharing documents or reading notes [16]. Discussion area creates a dynamic aspect in an online class. It allows students to actively communicate with each other and with their instructors. It also ensures students are actively involved in the learning process, rather than being passive recipients.

All three Learning Management Systems have multiple discussion areas or bulletin boards per course. The discussion areas enable students to interact with each other by responding to posts and sharing relevant ideas. Teachers can easily facilitate the online discussions by creating questions on the assignments/classwork tab. In all three systems, instructors can delete messages. Messages can be deleted when they are perceived as rude or irrelevant to the course. An instructors' ability to delete messages serves as a means of regulating the interaction amongst students. Google Classroom and Moodle all have a real-time chat feature that enables participants to engage in real-time synchronous discussions [15]. This is also a feature that E-loox, shares with Google Classroom and Moodle. The chat activity allows students to send instant messages 
International Journal of Software Engineering \& Applications (IJSEA), Vol.12, No.1, January 2021

to teachers and fellow students when they are logged into the site. When logged out, the sender has to wait for the recipients to log into the site before they can access the messages.

Both E-loox and Moodle users receive announcements on the login page. This is different with Google Classroom where announcements are made on the student dashboard page and the stream page respectively [15]. Another significant difference between these three systems lies in communication amongst students. While it is possible for student users of E-loox to email other students directly from the discussion areas, the same does not apply to Moodle and Google Classroom. In Google classroom for example, students have to click on the person they intend to email before clicking on the email icon box so they can send an email [12].

Table 3: Discussion area/Bulletin Board.

\begin{tabular}{|l|l|l|l|}
\hline \multicolumn{1}{|c|}{ Feature } & \multicolumn{1}{|c|}{ E-loox } & Moodle & Google Classroom \\
\hline $\begin{array}{l}\text { Multiple bulletin boards or discussion } \\
\text { areas per course. }\end{array}$ & $\checkmark$ & $\checkmark$ & $\checkmark$ \\
\hline Real time chat & $\checkmark$ & $\checkmark$ & $\checkmark$ \\
\hline Instructors can delete messages & $\checkmark$ & $\checkmark$ & $\checkmark$ \\
\hline $\begin{array}{l}\text { Users receive announcements on the login } \\
\text { page. }\end{array}$ & $\checkmark$ & & \\
\hline $\begin{array}{l}\text { Users can email posting authors directly } \\
\text { from the bulletin board. }\end{array}$ & $\checkmark$ & & \\
\hline
\end{tabular}

\subsection{Calendar}

The importance of a calendar to an online course cannot be emphasized enough. Students often ask questions like: when is the assignment due? Such questions can simply be answered by referring the student to the class calendar from where they can check out and confirm deadlines [15]. Knowing the deadlines can help students to plan in advance how to allocate their time to complete assignments within the given deadlines.

In E-loox, Moodle and Google Classroom, the calendar at the login page displays events from all courses. Students can simply click on the calendar to get a rough idea of what is due and hence what they should focus before time elapses.

Focusing on the differences, while it is possible for student users of Moodle to add entries to the course calendar at the instructor's discretion, the same is not possible in E-loox and Google classroom. Adding entries to the calendar can be beneficial in helping students plan in advance how to balance their assignments and co-curricular activities. Students can then customize calendars to meet with their needs. This is a more effective way of assisting students to plan on how to get things done prepare for events within and outside the academic realm.

Table 4: Calendar

\begin{tabular}{|l|l|l|l|}
\hline \multicolumn{1}{|c|}{ Feature } & E-loox & Moodle & Google Classroom \\
\hline $\begin{array}{l}\text { Calendar in the login page displays } \\
\text { events from all courses. }\end{array}$ & $\checkmark$ & $\checkmark$ & $\checkmark$ \\
\hline $\begin{array}{l}\text { Announcements from all courses display } \\
\text { in the login page. }\end{array}$ & $\checkmark$ & $\checkmark$ & $\checkmark$ \\
\hline $\begin{array}{l}\text { Instructors can add links to a calendar } \\
\text { entry }\end{array}$ & $\checkmark$ & $\checkmark$ & $\checkmark$ \\
\hline $\begin{array}{l}\text { Students can add entries to the course } \\
\text { calendar. }\end{array}$ & & $\checkmark$ & \\
\hline
\end{tabular}


International Journal of Software Engineering \& Applications (IJSEA), Vol.12, No.1, January 2021

\subsection{Audio/Video}

Lecture notes can get boring during an online course. When lecture notes become the order of the day, most students end up skimming through these notes rather than devoting their time and effort towards getting a clear understanding of the course content. 'Spicing up' an online course with audio and video material can limit skimming of the course content. A video or audio presentation of lectures and other relevant content will help students attach a voice to the content. It will further increase the interest of learners in the content. This particularly holds true to exceptional learners who need more than notes to understand course content.

All three LMSs can embed MP3, Real player and QuickTime player in pages [15]. They also allow users to add audio and video content that is stored within the courseware product. Additionally, all three allows users to add streaming PowerPoint presentations created with Real Video, Real Presenter, and Window Media Encoder as summarized in the following table:

Table 5: Audio/Video

\begin{tabular}{|l|l|l|l|}
\hline \multicolumn{1}{|c|}{ Feature } & E-loox & Moodle & Google Classroom \\
\hline Embed Real player in pages & $\checkmark$ & $\checkmark$ & $\checkmark$ \\
\hline Embed MP3 in pages. & $\checkmark$ & $\checkmark$ & $\checkmark$ \\
\hline Embed Quick Time player in pages. & $\checkmark$ & $\checkmark$ & $\checkmark$ \\
\hline $\begin{array}{l}\text { Add audio and video content stored within the courseware } \\
\text { product }\end{array}$ & $\checkmark$ & $\checkmark$ & $\checkmark$ \\
\hline $\begin{array}{l}\text { Add streaming PowerPoint presentation created with Real } \\
\text { Presenter, Real Video Window Media Encoder. }\end{array}$ & $\checkmark$ & $\checkmark$ & $\checkmark$ \\
\hline
\end{tabular}

\subsection{Chat/Whiteboard/Email}

Interactivity is a key factor in online courses [15]. Discussion areas should not be the only platform for interaction amongst students or between students and the instructor. As such, an instructor can incorporate synchronous learning through whiteboards and chatroom. A social studies teacher can, for example, have students engage in an online chat about the World War II. The instructor can allow different students to answer the questions by posting them in the whiteboard for other students to read and respond to. Instructors can also use whiteboards to conduct a review for an exam session.

Email is a key element in facilitating interactivity in an online course [15]. It provides a means of connecting students by facilitating communication. Instructors can use email to contact students and send additional notes to students who need them. Students can also use email to connect to the instructor and other students taking the course. Additionally, group members can also take advantage of the email features as a means of communicating with each other.

All three LMSs have an external email accessible through regular e-mail client, making it easier to contact other users. They also have multiple chatrooms in a single course which increases interaction amongst students and teachers. For all three systems, there is also a notification whenever a user enters the chatroom. Unlike Moodle and Google Classroom, E-loox has a restricted access to group chat rooms. This means that only members of a particular group can post and see the chats of their group. E-loox also has the option of private messaging in chat, an option that is not available for Moodle and Google Classroom users. While Google classroom and E-loox have the whiteboard feature that facilitates interaction, Moodle doesn't have it and the interaction is mainly through chat and email. Table 6 displays the interaction capabilities of these systems. 
International Journal of Software Engineering \& Applications (IJSEA), Vol.12, No.1, January 2021

Table 6: Chat/Whiteboard/E-mail

\begin{tabular}{|l|l|l|l|}
\hline \multicolumn{1}{|c|}{ Feature } & \multicolumn{1}{|c|}{ E-loox } & Moodle & Google Classroom \\
\hline $\begin{array}{l}\text { External e-mail (accessible through regular } \\
\text { e-mail client) }\end{array}$ & $\checkmark$ & $\checkmark$ & $\checkmark$ \\
\hline Multiple chat rooms. & $\checkmark$ & $\checkmark$ & \\
\hline Restricted access to group chat rooms. & $\checkmark$ & & \\
\hline Notifications when someone enters chat. & $\checkmark$ & $\checkmark$ & $\checkmark$ \\
\hline
\end{tabular}

\section{Monitoring Student Participation and Performance}

In all three LMSs, instructors can analyze the class through a combination of information, such as students who logged in on a particular day and posted a number of articles. Additionally, in all three, instructors can view a transcript of course chat room activity/discussion [15]. All three systems allow students to view their grades once posted. Instructors can also view the date and time for each student's first and last login.

This feature is helpful because it allows instructors to monitor the effort of each student towards excelling in the course. For all three, instructors can view the history for the total time spent online by each student throughout the entire course. However, instructors cannot view the number of bulletin board articles read by each student.

Table 7: Monitoring Student participation and performance

\begin{tabular}{|l|l|l|l|}
\hline \multicolumn{1}{|c|}{ Feature } & E-loox & Moodle & Google Classroom \\
\hline Instructors can analyze the class by combinations of information. & $\checkmark$ & $\checkmark$ & $\checkmark$ \\
\hline $\begin{array}{l}\text { Instructors can view how many bulletin board articles a student } \\
\text { has posted. }\end{array}$ & $\checkmark$ & & \\
\hline Instructors can view a transcript of course chat room activity. & $\checkmark$ & $\checkmark$ & $\checkmark$ \\
\hline Students can view their own grades & $\checkmark$ & $\checkmark$ & $\checkmark$ \\
\hline Instructors can view number of hits per page. & & $\checkmark$ & \\
\hline Instructors can view date and time of students' login & $\checkmark$ & $\checkmark$ & $\checkmark$ \\
\hline $\begin{array}{l}\text { Instructors can view the total time spent online by the student } \\
\text { throughout the course }\end{array}$ & $\checkmark$ & $\checkmark$ & $\checkmark$ \\
\hline
\end{tabular}

\subsection{Navigation and Interface}

New users of online classes often have a difficult time trying to navigate their way through the class [15]. While activities such as finding course content and responding to posts can be easy for instructors and previous users, it can prove to be a confusing task for new users. Instructors often aim to reduce as much as possible the frustrations of new student-users. They must pay attention to the structure, access and design of a course. When there is an overall ease in navigation, instructors will easily achieve their goals. Navigation is therefore considered a critical element in an LMS and instructors must select an LMS that minimizes student frustration and enhance learning.

In the three LMSs discussed in this paper, the courseware product defaults to graphic interface, allowing users to interact with visual indicators and graphical elements such as icons, buttons and windows, rather than text-based user interface [15]. This consequently motivates the students to interact with course content which would have otherwise been boring text-based content. To save on time spent in assignments and make creation of content easier for students, the courseware product automatically generates header and footer on new pages. 
International Journal of Software Engineering \& Applications (IJSEA), Vol.12, No.1, January 2021

In all three LMSs, an instructor can customize a background color or graphic. This is an important element that enables an instructor to create a graphic that resonates with the goals or theme of the class and increases student interaction with content [17]. Lastly, in all three, the courseware product can display components of the interface in a language other than English for student users [15]. This is particularly useful to learners with limited English proficiency who can take advantage of this feature to achieve a better understanding of course content.

Nevertheless, while the courseware product provides multiple button styles and icon in E-loox, the same doesn't apply to Google Classroom and Moodle. This makes Google classroom easier to navigate than the other two systems because students have an easier time finding out what they are looking for. Additionally, while E-loox allows users to view the course map, users of Moodle and Google classroom cannot view the course map. This also gives E-loox an advantage of the two aforementioned systems because students have a better understanding of what to expect of them throughout the course.

Table 8: E-loox, Moodle, and Google Classrom compared

\begin{tabular}{|l|l|l|l|}
\hline \multicolumn{1}{|c|}{ Feature } & E-loox & Moodle & Google Classroom \\
\hline $\begin{array}{l}\text { Courseware product defaults to graphic interface. } \\
\text { Courseware product automatically generates header and footer on } \\
\text { new pages. }\end{array}$ & $\checkmark$ & $\checkmark$ & $\checkmark$ \\
\hline $\begin{array}{l}\text { Instructor celect a custom background } \\
\text { color or graphic. }\end{array}$ & $\checkmark$ & $\checkmark$ & $\checkmark$ \\
\hline $\begin{array}{l}\text { Courseware product can display components of the interface in a } \\
\text { language other than English (in student-view only. }\end{array}$ & $\checkmark$ & $\checkmark$ & $\checkmark$ \\
\hline Courseware product provides multiple icon and button styles. & $\checkmark$ & & \\
\hline Users can view course map. & $\checkmark$ & & \\
\hline
\end{tabular}

\section{DisCuSSION}

In this section, we will discuss and evaluate what we found, and how it relates to our literature review. We will also interpret the results listed in the tables.

We compared the features related to content development in the Table 1. Although we cannot claim to be winner on most features, we want to emphasize that our system enables students and instructors to edit uploaded texts online. This feature is crucial for developing countries where majority of students do not have internet access at home.

We compared several features in Tables 2 though 8. From those seven tables, we can observe that the features are very similar to each other. However, we want to emphasize that our system is a very cost-effective solution especially for developing countries.

\section{CONClusion}

A learning management system should address the needs of the ultimate end user; the learner. Each LMS has key features that aim to motivate students to actively engage with the course content. E-loox has been designed specifically for students located in areas with limited Internet access. As a hybrid app, E-loox allows students to complete assignments, access course materials, and conduct research in places where there is no internet access. It is an innovative tool that advances distance learning opportunities in Somalia, where internet penetration rate is less than 7 percent. E-loox is cost-effective and can modernize the current Somali educational system. E- 
International Journal of Software Engineering \& Applications (IJSEA), Vol.12, No.1, January 2021

loox is different from other LMS because it's cheaper and comes with a technical support system. E-loox is seeking partnerships with Somali Ministry of Education to subsidize the hardware costs for students who do not have the financial means to purchase a device. When E-loox is fully adopted by all schools in Somalia, it will renovate how education is delivered in Somalia.

\section{REFERENCES}

[1] Machado, M., \& Tao, E. (2007, October). E-loox vs. Moodle: Comparing user experience of learning management systems. In 2007 37th annual frontiers in education conference-global engineering: Knowledge without borders, opportunities without passports (pp. S4J-7). IEEE.

[2] Paulsen, M. F. (2003). Experiences with learning management systems in 113 European institutions. Journal of Educational Technology \& Society, 6(4), 134-148.

[3] Cavus, N., \& Zabadi, T. (2014). A comparison of open source learning management systems. Procedia-Social and Behavioral Sciences, 143, 521-526.

[4] United Nations (2017). Sustainable Development Goals. Retrieved from https://www.un.org/sustainabledevelopment/education

[5] Hanushek, E. A., \& Wößmann, L. (2007). Education quality and economic growth. The World Bank.

[6] McLaugh, C. (2016, April 20). The Homework Gap: The 'Cruelest Part of the Digital Divide' neaToday. Retrieved from http://neatoday.org/2016/04/20/the-homework-gap/

[7] Muilenburg, L. Y., \& Berge, Z. L. (2005). Student barriers to online learning: A factor analytic study. Distance education, 26(1), 29-48.

[8] Hali Access Network. (2015). Education Facts Sheet - Somaliland (pdf). Retrieved from http://haliaccess.org/wp-content/uploads/2018/05/Somaliland-country-fact-sheet-.pdf

[9] Costa, C., Alvelos, H., \& Teixeira, L. (2012). The use of Moodle e-learning platform: a study in a Portuguese University. Procedia Technology, 5, 334-343.

[10] Moodle. (2016, October 19). Online learning that you can access offline? Welcome to Moodle Mobile 3.1.3. Retrieved from https://moodle.com/news/online-learning-can-access-offline-welcomemoodle-mobile-3-1-3/

[11] Maněnová, M. (2013) Options of using the Moodle e-learning system for education by means of mobile devices. In. Trend of the Education.

[12] Zhang, M. (2017). Teaching with Google Classroom. Packt Publishing Ltd.

[13] Google. (2019). Work on Google Docs, Sheets \& Slides offline. Retrieved from https://support.google.com/docs/answer/6388102?co=GENIE.Platform\%3DDesktop\&hl=en

[14] Dobre, I. (2015). Learning Management Systems for higher education-an overview of available options for Higher Education Organizations. procedia-social and behavioral sciences, 180, 313-320.

[15] Lewis, B. A., MacEntee, V. M., DeLaCruz, S., Englander, C., Jeffrey, T., Takach, E. \& Woodall, J. (2005, June). Learning management systems comparison. In Proceedings of the 2005 Informing Science and IT Education Joint Conference (pp. 17-29).

[16] Northrup, P. (2009). Online learners' preferences for interaction. The perfect online course: Best practices for designing and teaching, 463-473.

[17] Landay, S. (2010). Online Learning 101: Part I: Authoring and Course Development Tools. eLearn Magazine, 2010(6), 2.

\section{AUTHORS}

Dr. Bilal Gonen is an Assistant Professor in the School of Information Technology at the University of Cincinnati. He has expertise in cloud computing, IT infrastructure, Blockchain, Virtualization, AWS, Hyper-V, Machine Learning, Programming in Java, $\mathrm{C}, \mathrm{C}++$, Python.

Badri Jimale is a graduate master's student in the School of Information Technology at the University of Cincinnati.
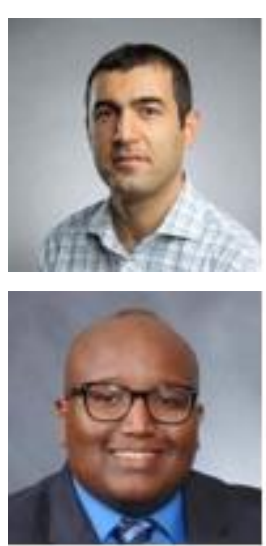